Research Article

\title{
The Impact of Financial Risks on Financial Investment in Infrastructure: Based on a Two-Factor Stochastic Differential Equation
}

\author{
Qiming Zhang $\mathbb{D}$, Xuemeng Guo, and Hongchang $\mathrm{Li}$ \\ School of Economics and Management, Beijing Jiaotong University, Beijing 100044, China \\ Correspondence should be addressed to Qiming Zhang; 17113161@bjtu.edu.cn and Hongchang Li; hchli@bjtu.edu.cn
}

Received 11 May 2021; Revised 26 August 2021; Accepted 4 September 2021; Published 21 October 2021

Academic Editor: Emilio Jiménez Macías

Copyright ( 2021 Qiming Zhang et al. This is an open access article distributed under the Creative Commons Attribution License, which permits unrestricted use, distribution, and reproduction in any medium, provided the original work is properly cited.

\begin{abstract}
Financial risks, such as inflation and interest rate changes, significantly affect the costs and benefits of infrastructure projects. Nevertheless, there is a dearth of research concerning financial investment (government subsidies) for infrastructure projects in the context of inflation and interest rate changes. Accordingly, this study builds a stochastic differential equation model based on inflation rate and interest rate, through which the expression of government subsidies in public-private partnership is optimised. Specifically, the Monte Carlo simulation was used to undertake a calculation of the present value of operating loss subsidy and risk-sharing subsidy for the $N$ City Metro Line 3. Subsequently, the effect of inflation, nominal interest rates, interest rate volatility, as well as inflation volatility, on the present value of operating loss subsidies was investigated. It was established that the dynamic random discount rate based on inflation rate and interest rate may effectively simulate the effect of inflation rate and interest rate changes on project operating loss. Moreover, it is feasible to calculate the present value of the risk-adjusted operating loss subsidy and the present value of the risk-sharing subsidy. Inflation rate, inflation volatility, and interest rate volatility are positively correlated with the present value of operating loss subsidies, whereas the interest rate is negatively correlated with the present value of inflation-adjusted operating loss subsidies. Inflation volatility has the greatest effect on the present value of subsidies, followed by interest rate volatility and inflation rate. Ultimately, this paper provides an effective tool for quantitative simulation of and risk-sharing in public-private partnership projects, which can facilitate a regional economy's sustainable development.
\end{abstract}

\section{Introduction}

Given that infrastructure projects have public welfare and quasi-commercial aspects, it is far from straightforward to anticipate that decent revenue may be derived from social capital. Generally, local governments distribute some subsidies to facilitate such social capital becoming proactively involved in infrastructure projects. In 2014, the Ministry of Finance issued the Operation Guide for Government-Private Capital Cooperation Model (Trial) [1], hereafter referred to as Guidelines, identifying that viability gap funding is a significant source of a project's income in relation to social capital. Nevertheless, regarding financial investment (government subsidies) in infrastructure projects, the challenges of insufficient subsidies and excessive subsidies are raised during the implementation process. Insufficient subsidies potentially deter social capital from investing in projects, whereas excessive subsidies potentially result in the loss of state assets, corruption, and further problems. The existing research into public-private partnership government subsidies has concentrated primarily on two aspects. One is the calculation of reasonable government subsidies via means of real option and option game model, while the other is research into government subsidy mechanisms and risksharing via the evolutionary game model. Contrastingly, limited research has focused on the inflation and discount rate, although these are the principal parameters involved in the calculation of government subsidies for infrastructure projects.

Generally, infrastructure projects timescale exceeds 20 years, with financial risks, such as inflation fluctuation and interest rate fluctuation, likely to have a tremendous effect 
on them [2-5]. Therefore, inflation is one of the principal risks faced confronting such projects. Increased labour and operating costs stemming from inflation have a significant effect on the income of infrastructure projects $[2,6-8]$. For example, inflation in Argentina since 2002 has resulted in a dramatic increase in organisational costs for parties involved in the Buenos Aires water system infrastructure project. The government locked the charges for the water supply system with the aim of maintaining social stability, which ultimately caused the withdrawal of social capital. A further example is how inflation in China in 1994 significantly raised the social capital costs of those participating in the GuangzhouShenzhen-Zhuhai project, causing heavy losses. A similar process occurred relating to Pakistan's Karachi power project, the North-South Highway project in Malaysia, and the Prince Edward Island Bridge in Canada $[9,10]$. In addition, the interest rate is a significant parameter in the value evaluation system of infrastructure projects [6]. Generally, the government is supposed to establish an appropriate interest rate as the discount parameter for the DCF valuation of infrastructure projects, with fluctuation of the interest rate having a tremendous effect on how government subsidies are calculated. Even so, due to financial uncertainty concerning risks, for example, inflation and interest rate changes, the interest rate has often been measured poorly as part of the current infrastructure project evaluation process [11-15]. Challenges relating to the transaction process will result in poor performance of public-private partnership projects [16]. Thus, the ambiguities surrounding infrastructure projects must be comprehensively considered during the decision-making evaluation process; otherwise, there is a strong risk that the government's subsidies required for investment in the projects will be underestimated. The unreasonable distribution of risks relating to uncertainty between the government and social capital may result in the withdrawal of social capital and failure of the infrastructure projects. Consequently, identifying an appropriate method for conducting a more scientific simulation of the effect of inflation, interest rate, and risk-sharing on government subsidies, in addition to the calculation of a more reasonable present value of government subsidies in publicprivate partnership, is meaningful to investigate.

\section{Literature Review}

2.1. Discount Rate of Government Subsidy. Generally, the annual discount rate of the net present value of government subsidies must be considered for the year in which the fiscal subsidy expenditure occurs. This should also be determined on a reasonable basis by referring to the yield of local government bonds over the identical time period. However, this method does not account for the increase in costs as well as incomes stemming from inflation. Accordingly, the extant research on government subsidies for infrastructure projects typically provides a comprehensive appraisal of the two factors of interest rate and inflation rate. Burinskas and Burinskiene [17] measured the growth of Lithuania's transportation sector by applying Gordon's growth model. Furthermore, Prianka and Malik [11] investigated infrastructure projects in the form of franchising, providing the calculation expression of operating costs during the $j$ th year as follows: $\mathrm{OMC}_{j}=c_{m} \prod_{k=0}^{j}\left(1+f_{k}^{M}\right)$, where $c_{m}$ presents the initial annual operating cost of the project, while $f_{k}^{M}$ is the growth coefficient in light of inflation.

Shen et al. [12] calculated the net present value (NPV) of the concession period for infrastructure BOT projects, considering the discount rate of the government and the private sector to be formulated as follows:

$$
d=\frac{(1+I)}{\left(1+I_{n f}\right)}-1,
$$

where $I$ represents the interest rate, while $I_{n f}$ represents the inflation rate. Based on these two rates, Shen and $\mathrm{Wu}$ [13] calculated the risk-adjusted build-operate-transfer (BOT) project concession period NPV. To reflect the discount rate change during the concession period, the discount rate has been determined to comply with the normal distribution, with the discount rate simulated using the Monte Carlo simulation. Furthermore, Wu et al. [14] calculated the net transfer value of BOTprojects, while Hanaoka and Palapus [15] investigated the reasonable concession period of BOT projects in the Philippines. All of these researchers adopted formula (1) as a means of calculating the discount rate for public sector subsidies.

Certain studies have determined that the method of estimating inflation and interest rates as part of the current government subsidy calculation procedure is rather straightforward. The effect cannot be conveyed by the inflation and interest rates of government subsidies during the franchise over 20 to 30 years. Moreover, the traditional model may reflect the risk-sharing between the government and social capital to a limited extent. Accordingly, this study will enhance this process in this regard.

2.2. Inflation Rate and Interest Rate. With the aim of simulating the impact of infrastructure project government subsidies on inflation, the infrastructure project's future cash flow must be amalgamated with the term structure of interest rate and inflation rate. In accordance with the stochastic differential equation model which adheres to geometric Brownian motion, Scholes and Black [18] proposed the Black-Scholes option pricing formula. This has proven to be a significant breakthrough for the stochastic differential equation in the asset pricing field. Subsequently, Merton [19] assumed that the bond price follows geometric Brownian motion and priced it accordingly, although the trend between the bond price and the stock price is particularly different. Via statistical research, it has been determined that the interest rate has the characteristics of mean reversion. Consequently, Vasicek [20] adopted a stochastic differential equation with mean reversion to represent the dynamic process of interest rate, ultimately devising the Vasicek model. Cox et al. [21] proposed an alternative stochastic differential equation model referred to as the CIR model, to represent the dynamic process of interest rate. Given that the interest rate cannot be negative in the CIR model, this diverges from the Vasicek model. In addition, Heath et al. [22] considered there to be a connection between the drift rate and the standard deviation 
of the forward interest rate, ultimately proposing the HJM model. Concerning the pricing of inflation-related derivatives, Jarrow and Yildirim [23] stripped standard coupon bonds to obtain real and nominal zero-coupon bond price curves. Following this, by fitting a three-factor arbitrage-free term structure model with the time series data of the consumer price index (CPI) in addition to real and nominal zerocoupon bond price curves, the term structure parameters were estimated, and the pricing of inflation index call options was completed. By combining the Vasicek model and CIR model, Pelizzari and Paolo [24] proposed a stochastic model based on interest rates and the CPI index; this was verified based on TIPS price data published by the Federal Reserve. The researchers suggested that the model could effectively fit TIPS pricing. Nevertheless, this model did not adopt the standard method of cross-sectional estimation of the term structure in relation to the real interest rate, instead simplifying the estimation process. Abrahams et al. [25] adopted an affine term structure model with six principal components extracted from treasury bond yields and TIPS to price the US Treasury inflation index bonds. In addition, certain academics have adopted statistical-econometric methods for investigating inflation's effect on the capital market, as well as the effect of monetary policy on the consumer market $[26,27]$. According to the above analysis, given that the option pricing formula was established in 1973, the stochastic differential equation has been pervasively adopted in the asset pricing field. Particularly in terms of simulating the asset price trend, the stochastic differential equation plays an irreplaceable role.

The major challenge in terms of simulating the discount rate of government subsidies pertains to the complexity of its financial structure. Therefore, it is necessary to combine future government subsidies with interest rates and inflation rates, in addition to inflation risk-sharing between the government and private sector. Nevertheless, as previous research has determined, the calculation method for formula (1) that is typically applied by academics cannot comprehensively and effectively convey the dynamic changes in inflation and interest rates, while usually failing to establish the share of inflation risk between the government and the private sector. In certain studies of interest rates and inflation rates, academics have attempted to distinguish interest rates and inflation rates from TIPS bond yields. Other researchers, for example, Pelizzari and Paolo [24], sought to adopt other perspectives to fit TIPS via the interest rate and CPI index, ultimately obtaining sound outcomes. In the environmental risk field, people adopt the ELECTRE model and multicriteria decision analysis methods for decision analysis, whereas in the financial risk field, people seldom adopt complex models to investigate the effect of associated risk factors on infrastructure $[28,29]$. As China did not issue TIPS-like inflation protection bonds, this research will apply the inflation underpricing method to establish a two-factor stochastic differential equation model of interest rate and inflation rate, thus enabling calculation of discount rates based on formula (1) combined with Pelizzari and Paolo's research. Subsequently, the present value of government subsidies is calculated, and the risk-sharing parameters are established, as a means of simulating risk-sharing between the government and private sector. This research considers the effect of interest rates and inflation rates on government subsidies across various periods, which also reflects the risk-sharing principle.

Three major contributions are made by this article. Firstly, it provides an innovative tool for calculating government subsidies. The stochastic differential equation model is applied for optimising the calculation method for the discount rate of government subsidies, with the government subsidy calculation model based on interest rates and inflation rates being proposed. Secondly, it provides a risk-sharing method for public-private partnership. The risk-sharing parameter is incorporated into the government subsidy calculation model, with the government subsidy amount under the change of risk-sharing being calculated, while the effect of toll adjustment frequency on government subsidies is investigated. This research observes the effect of interest rate, inflation rate, and interest rate volatility, as well as inflation volatility, on government subsidies based on the modelling, with meaningful conclusions being drawn.

\section{Modelling}

The computation model of the present value of the government's operation loss subsidy may be expressed as follows:

$$
S=\sum_{0}^{T} \frac{C_{t}-I_{t}}{(1+d)^{t}}, \quad 0 \leq t \leq T .
$$

In formula (2), $C_{t}$ refers to the infrastructure project's operating cost; $I_{t}$ refers to the infrastructure project's operating income; and $S$ represents the present value of the operation loss subsidy calculated based on the operating cost, operating income, and the discount rate $I_{t}$ (hereafter referred to as the subsidy's present value). Nevertheless, discount rate $d$ in the model does not account for the increased costs caused by inflation. Furthermore, in general, in the numerical calculation, discount rate $d$ pertains to the interest rate for local government bonds during the current year, which might not reflect interest rate changes over the 30 -year construction and operation period. Consequently, based on formula (1) and in accordance with Pelizzari's research, a two-factor discount rate model has been constructed based on the inflation rate and interest rate.

Following this, the research incorporated the inflation rate $i(t)$ and the nominal interest rate $r(t)$. The inflation rate $i(t)$ and the nominal interest rate $r(t)$ are compliant with Vasicek's [20] stochastic differential equation model. $r(t)$ and $i(t)$ may be expressed as the following dynamic random process:

$$
\begin{aligned}
& d i(t)=\left(\alpha_{i}-\beta_{i} i(t)\right) \mathrm{d} t+\sigma_{i} \mathrm{~d} W_{i}(t), \\
& d r(t)=\left(\alpha_{r}-\beta_{r} r(t)\right) \mathrm{d} t+\sigma_{r} \mathrm{~d} W_{r}(t) .
\end{aligned}
$$

In formulas (3) and (4): $\alpha_{i}, \beta_{i}, \alpha_{r}, \beta_{r}, \sigma_{i}$, and $\sigma_{r}$ are constants; $\alpha_{i} / \beta_{i}$ is the long-term equilibrium inflation rate; $\sigma_{i}$ is the inflation rate volatility; $\alpha_{r} / \beta_{r}$ is the long-term equilibrium interest rate; $\sigma_{r}$ is the nominal interest rate volatility; $W_{i}(t)$ and $W_{r}(t)$ are both standard Brownian motion in the probability space; $F$ is the $\sigma$ algebra of the sample space $\Omega$ 
which makes the probability a defined subset, while $P$ is a probability measure. This research assumes that $W_{i}(t)$ and $W_{r}(t)$ are correlated, as in the case $d W_{i}(t) d W_{r}(t)=\rho_{i, r} \mathrm{~d} t$.

Typically, the government provides subsidies on an annual basis to the social capital participating in the infrastructure project. The principal component of the subsidy includes labour costs as well as operation and maintenance costs, with all of these costs being affected by the inflation rate. The corresponding government subsidies increase when the inflation rate rises and surpasses the social capital commitment, whereas deflation occurs and the government subsidy amount diminishes when the inflation rate decreases. It is assumed that the prices of public goods will be adjusted in accordance with inflation. As the aforementioned features convey, the expression of the government operation loss subsidy amount $\mathrm{CF}_{t}$ at time $t$ is

$$
\mathrm{CF}_{t}=\left(C_{t}-I_{t}\right) \max \left(\mathrm{CI}_{t}-q, 1\right)
$$

$\mathrm{CI}_{t}$ indicates the cumulative inflation rate when calculating the year $t$ subsidy amount. $\mathrm{CI}_{t}=e^{D_{i}(0 . t)}$ represents the random compound change of the inflation rate between time 0 and time t. $q$ represents the social capital's exposure to inflation risk. $D_{i}(0 . t)$ takes the following form [20]. With $\lambda_{i}$ and $\lambda_{r}$ presenting the market price risk of inflation rate and nominal interest rate, respectively:

$$
D_{i}(0 . t)=\int_{0}^{t} i(s) \mathrm{d} s+\int_{0}^{t} \lambda_{i}(s) \mathrm{d} W_{i}(t)-\frac{1}{2} \int_{0}^{t} \lambda_{i}^{2}(s) \mathrm{d} s, \quad t>0 .
$$

The process entails discounting the government operation loss subsidy $\mathrm{CF}_{t}$ from time $t$ to time 0 during each year of project operation, according to the Guidelines. $e^{D_{r}(0 . t)}$ is used to represent the random compound discount process of the nominal interest rate, where

$$
D_{r}(0 . t)=-\int_{0}^{t} r(s) \mathrm{d} s+\int_{0}^{t} \lambda_{r}(s) \mathrm{d} W_{i}(t)-\frac{1}{2} \int_{0}^{t} \lambda_{r}^{2}(s) \mathrm{d} s, \quad t>0 .
$$

With $E$ representing the expectation of a random process, the present value $\mathrm{PC}_{t}$ of $\mathrm{CF}_{t}$ can be expressed as follows:

$$
\mathrm{PC}_{t}=\left(C_{t}-I_{t}\right) E\left[\max \left(e^{D_{i}(0 . t)}-q, 1\right) e^{D_{r}(0 . t)}\right]
$$

In formula (8), $E\left[\max \left(e^{D_{i}(0 . t)}-q, 1\right) e^{D_{r}(0 . t)}\right]$ represents the expectation regarding the discount rate in relation to the operating costs. For convenience, $\max \left(e^{D_{i}(0 . t)}-q, 1\right)$ may be tagged as the inflation operator $\mathrm{IA}_{t}$, while $e^{D_{r}(0 . t)}$ can be tagged as the discount operator $\mathrm{RA}_{t}$. As a means of obtaining the expression of $\mathrm{PC}_{t}$, the risk-neutral method [19] may be adopted to convert the actual measure $P$ into a risk-neutral measure $\widetilde{P}$. Subsequently, $i(t)$ and $r(t)$ are martingales under $\widetilde{P}$. According to Gossanov's theorem and Radonian Condim derivative, the inflation rate $i(t)$ and the nominal interest rate $r(t)$ may be expressed in the following manner under the probability measure $\widetilde{P}$ :

$$
\begin{aligned}
d \tilde{i}(t) & =\left(a_{i}-b_{i} i(t)\right) \mathrm{d} t+\sigma_{i} \mathrm{~d} \widetilde{W}_{i}(t), \\
d \widetilde{r}(t) & =\left(a_{r}-b_{r} r(t)\right) \mathrm{d} t+\sigma_{r} \mathrm{~d} \widetilde{W}_{r}(t) .
\end{aligned}
$$

$a_{x}=\alpha_{x}+\lambda_{x} \sigma_{x}, \quad b_{x}=\beta_{x}, \quad d \tilde{W}=-\lambda_{x} \mathrm{~d} t+d W(t), \quad$ and $x=i, r . \widetilde{W}(t)$ is the standard Brownian motion under $\widetilde{P}$, while $d \widetilde{W}_{r}(t) d \widetilde{W}_{i}(t)=\rho_{i, r} \mathrm{~d} t$. Under the risk-neutral measure we have

$$
\begin{aligned}
\mathrm{PC}_{t} & =\left(C_{t}-I_{t}\right) E\left[\max \left(e^{\widetilde{D}_{i}(0 . t)}-q, 1\right) e^{\widetilde{D}_{r}(0 . t)}\right], \\
\widetilde{D}_{i}(0 . t) & =\int_{0}^{t} \widetilde{i}(s) \mathrm{d} s, \\
\widetilde{D}_{r}(0 . t) & =-\int_{0}^{t} \widetilde{r}(s) \mathrm{d} s .
\end{aligned}
$$

The Vasicek stochastic differential equation of interest rate has an explicit solution:

$$
\widetilde{i}(t)=e^{-b_{i} t} \operatorname{IR}(0)+\frac{a_{i}}{b_{i}}\left(1-e^{-b_{i} t}\right)+\sigma_{i} e^{-b_{i} t} \int_{0}^{t} e^{b_{i} s} \mathrm{~d} \tilde{W}_{i}(s) .
$$

While the stochastic differential equation has the following form:

$$
\widetilde{i}(t)-\widetilde{i}(0)=\int_{0}^{t}\left(a_{i}-b_{i} \widetilde{i}(s)\right) \mathrm{d} s+\int_{0}^{t} \sigma_{i} \mathrm{~d} \widetilde{W}_{i}(s) .
$$

Substitute equation (13) into equation (14), we obtain

$$
\widetilde{D}_{i}(0 . t)=\int_{0}^{t} \widetilde{i}(s) \mathrm{d} s=\frac{a_{i} t}{b_{i}}+\left(\widetilde{i}(0)-\frac{a_{i}}{b_{i}}\right)\left(\frac{1-e^{-b_{i} t}}{b_{i}}\right)+\frac{\sigma_{i}}{b_{i}} \int_{0}^{t}\left(1-e^{-b_{i} t} e^{a_{i} s}\right) \mathrm{d} \widetilde{W}_{i}(s) .
$$

Similarly, the discount operator $\mathrm{RA}_{t}$ may be expressed as

$$
\begin{aligned}
e^{\widetilde{D}_{r}(0 . t)} & =\exp \left\{-\int_{0}^{t} \widetilde{r}(s) \mathrm{d} s\right\} \\
& =\exp \left\{-\left(\frac{a_{r} t}{b_{r}}+\left(\tilde{i}(0)-\frac{a_{r}}{b_{r}}\right)\left(\frac{1-e^{-b_{r} t}}{b_{r}}\right)+\frac{\sigma_{r}}{b_{r}} \int_{0}^{t}\left(1-e^{-b_{r} t} e^{a_{r} s}\right) \mathrm{d} \widetilde{W}_{r}(s)\right)\right\} .
\end{aligned}
$$


According to the properties of Ito integrals, let $M_{i t}=E$ $\left(\widetilde{D}_{i}(0 . t)\right)=a_{i} t / b_{i}+\left(\widetilde{i}(0)-a_{i} / b_{i}\right)\left(1-e^{-b_{i} t} / b_{i}\right), \mathrm{Cum}_{i t}=\mathrm{V}$ $\operatorname{ar}_{i}\left(\widetilde{D}_{i}(0 . t)\right)=\int_{0}^{t} a_{i}^{2} / b_{i}^{2}\left(1-e^{-b_{i} t} e^{a_{i} s}\right)^{2} \mathrm{~d} s$, and $Y=-\sigma_{i} / b_{i} \int_{0}^{t}$ $\left(1-e^{-b_{i} t} e^{a_{i} s}\right) \mathrm{d} \widetilde{W}_{i}(s) / \sqrt{\int_{0}^{t} a_{i}^{2} / b_{i}^{2}\left(1-e^{-b_{i} t} e^{a_{i} s}\right)^{2} \mathrm{~d} s} \sim N(0,1)$.
$A_{t}$ is

$$
\begin{aligned}
& E\left[\max \left(e^{\widetilde{D}_{i}(0 . t)}-q, 1\right)\right] \\
& =E\left\{\left(e^{\widetilde{D}_{i}(0 . t)}-q\right) \mid e^{\widetilde{D}_{i}(0 . t)}>1+q\right\}+E\left\{1 \mid e^{\widetilde{D}_{i}(0 . t)}>1+q\right\} \\
& =\frac{1}{\sqrt{2 \pi}} \int_{-\infty}^{\log ^{1 /(1+q)}+M_{i t} / \sqrt{\operatorname{Cum} V_{\mathrm{it}}}} \exp \left\{M_{\mathrm{it}}-\sqrt{\operatorname{Cum} V_{\mathrm{it}}} Y\right\} e^{-\left(Y^{2} / 2\right)} \mathrm{d} Y-\frac{1}{\sqrt{2 \pi}} \int_{-\infty}^{\log ^{1 /(1+q)}+M_{i t} / \sqrt{\operatorname{Var}_{\mathrm{it}}}} e^{-\left(Y^{2} / 2\right)} \mathrm{d} Y+1 \\
& =e^{M_{i t}+\left(\operatorname{Cum} V_{i t} / 2\right)} N\left(\frac{\log ^{1 /(1+q)}+M_{\mathrm{it}}+\operatorname{Cum} V_{\mathrm{it}}}{\sqrt{\operatorname{Cum} V_{\mathrm{it}}}}\right)-N\left(\frac{\log ^{1 /(1+q)}+M_{\mathrm{it}}}{\sqrt{\operatorname{Cum} V_{\mathrm{it}}}}\right)+1
\end{aligned}
$$

In summary, from formulas (2), (11), (16), and (17), the expression of the present value $S$ of the government subsidy is

$$
\begin{aligned}
S & =\sum_{0}^{\mathrm{T}} \mathrm{PC}_{t}=\sum_{0}^{\mathrm{T}}\left(C_{t}-I_{t}\right) E\left[\mathrm{IA}_{t} \times \mathrm{RA}_{t}\right] \\
& =\sum_{0}^{\mathrm{T}}\left\{\left(C_{t}-I_{t}\right) E\left[\max \left(e^{\widetilde{D}_{i}(0 . t)}-q, 1\right) e^{\widetilde{D}_{r}(0 . t)}\right]\right\} \sum_{0}^{T} \\
& =\sum_{0}^{\mathrm{T}}\left\{\left(C_{t}-I_{t}\right)\left[e^{M_{i t}+\operatorname{Cum} V_{\mathrm{it}} / 2} N\left(\frac{\log ^{1 /(1+q)}+M_{\mathrm{it}}+\operatorname{Cum} V_{\mathrm{it}}}{\sqrt{\operatorname{Cum} V_{\mathrm{it}}}}\right)-N\left(\frac{\log ^{1 /(1+q)}+M_{i t}}{\sqrt{\operatorname{Cum} V_{i t}}}\right)+1\right] E\left(e^{\widetilde{D}_{r}(0 . t)}\right)+\left(C_{t}-I_{t}\right) \operatorname{Cov}_{t}\right\} .
\end{aligned}
$$

The main aspect of the subsidy present value expression (18) is the expression of the discount rate $E\left[\max \left(e^{\widetilde{D}_{i}(0 . t)}\right.\right.$ $\left.-q, 1) e^{\widetilde{D}_{r}(0 . t)}\right]$. It may be established from the formula structure that the government subsidy $\left(C_{t}-I_{t}\right)$ per period is linked to the inflation operator $\mathrm{IA}_{t}$ and discount operator $\mathrm{RA}_{t}$ of the current period. This conveys how the characteristics are affected by both interest rates and inflation rates. The risk-sharing parameter $q$ in the inflation operator reflects the government's assumption of inflation risk for the cash flow per period.

\section{The Application of the Government Subsidy Model}

4.1. Basic Information concerning the Project. The N City Metro Line 3 plans to implement a public-private partnership for investment and construction. The civil construction project was initiated towards the end of 2016, with an expectation that it will enter into operation by the end of 2020. The line's total length is approximately $28.34 \mathrm{~km}$, with all of the lines being laid underground. A total of 22 stations will be constructed, with the mean station spacing being $1.33 \mathrm{~km}$; the largest station spacing is $2.235 \mathrm{~km}$, while the smallest station spacing is $0.607 \mathrm{~km}$. The project's total investment is approximately 21.585 billion CNY. The BOT mode of mechanical and electrical equipment is adopted, which is to say, the PPP mode of Part A plus Part B. The project's financial analysis and calculation period is 28 years, during which time the construction period will be 3 years (2018-2020), while the franchise operation period is 25 years (2021-2045, including a trial operation during 2021).

According to the viability gap funding subsidy formula presented in the Guidelines, the government adopts partial responsibility for direct payment during the project's operating subsidy period. The annual direct government payments include the annual mean construction costs and operating loss subsidies undertaken by the social capital. As the construction costs have been determined following the conclusion of the construction period, this study will concentrate primarily on the simulation calculation for the annual operating loss subsidies. 
4.2. Data Resources. Firstly, regarding the instantaneous nominal interest rate, the content in the Guidelines stipulates that "When considering the annual discount rate, the year in which fiscal subsidy expenditures occurred should be taken into account, with reference to the yield of local government bonds over the same period reasonably." The government bond yield (0-year/overnight) is adopted to measure the instantaneous nominal interest rate level. Accounting for the data availability issue-given that the time interval for China Bond local government debt data provided in the Wind database is for the period from 4 January to the present-the beginning of the nominal interest rate measurement period in this research is 4 January 2010. As the project has been operational since 2021, 4 January 2020 is the deadline for data selection. Consequently, the time interval for data selection is between 4 January 2010 and 2 January 2020, with a sample size of 2402. Given that this is a continuous time model, linear interpolation is adopted for filling in the data gaps for legal holidays.

This research considers the monthly data for the consumer price index published by the National Bureau of Statistics of China (previous month $=100$ ) as a means of measuring the inflation rate. The data interval provided in the Wind database is from January 1995 to the present. To match the cut-off date of the interest rate data, as well as to cover the inflation rate's historical changes to the greatest extent possible, this article selects the data interval of January 1995 to January 2020. Given that the CPI data released by the National Bureau of Statistics of China are monthly, it is necessary to convert those into daily ones. This article will apply the linear interpolation to transform CPI data, while as a means of ensuring data availability, one period lagging CPI data will be used. Consequently, the CPI data (indicated by $\mathrm{CPID}_{t}$ ) on the $d$ day of the $m$ th month following the initiation of the operation period may be stated as follows:

$$
\mathrm{CPID}_{t}=\mathrm{CPI}_{m-2}+\frac{d-1}{g_{m}}\left(\mathrm{CPI}_{m-1}-\mathrm{CPI}_{m-2}\right),
$$

with $g_{m}$ being the total number of days in the $m$ th month following the project starting operating, while $\mathrm{CPI}_{m}$ is the actual price index in the $m$ th month. The collected daily data for $\mathrm{CPID}_{t}$ are processed to obtain daily data for inflation rate $i$. Table 1 presents the descriptive statistics for the data.

4.3. Parameter Estimation. According to the calculation formula (18) for the present value of subsidy $S$, nine parameters must be estimated for the calculation, namely: $\alpha_{i}, \beta_{i}, \sigma_{i}, \lambda_{i}, \alpha_{r}, \beta_{r}, \sigma_{r}, \lambda_{r}$, and $\operatorname{Cov}_{t}$.

According to models (2) and (3), $i(t)$ and $r(t)$ are both stochastic differential equations under actual measurement $P$. Generally, the random difference method is adopted for estimating the stochastic differential equation model's parameters. By setting $d t=1$, equations (2) and (3) can be rewritten as

$$
x(t)=\alpha_{x}+\left(1-\beta_{x}\right) x(t-1)+\varepsilon_{x}(t) ; x=i, r .
$$

To test the correlation of the disturbances in models (2) and (3), it is necessary to make a combined estimation of $i(t)$ and $r(t)$, applying the Breusch-Pagan test. This article considers the interest rate and inflation rate data from 4 January 2010 to 2 January 2020, adopting the seemingly uncorrelated regression means to calculate. This method is appropriate for regression equations which potentially include related disturbances. The $p$ value of the Breusch-Pagan test is 0.9654 . Accordingly, the null hypothesis may be accepted that "the disturbances of each equation are mutually independent", namely $\rho=0$, with the parameter being set to $\operatorname{Cov}_{t}=0$.

Since changes in the related parameters could be observed over a long period of time, this paper adopted the rolling regression method. The first-year data for inflation and interest rates were analysed as the basic samples, with the sample range then gradually expanded. Subsequently, the daily parameter values for the inflation rate between January 1996 and January 2020, in addition to the interest rate between January 2011 and January 2020, were obtained. The changes are presented in Figures 1 and 2.

The results in Figure 1 show that $\alpha_{i}$ and $\beta_{i}$ fluctuated significantly prior to 2001, after which they became gradually more stable. The value of $\sigma_{i}$ remained high prior to 2002, although declined gradually afterwards. This may be a consequence of the drastic economic fluctuation in China before 2000. Post-2000, following the launch of a more stable monetary policy, the inflation rate has become increasingly robust over a long period of time. It is evident from Figure 2 that $\alpha_{i}, \beta_{i}$, and $\sigma_{i}$ have become increasingly stable post-2013; thus they may be deemed suitable to establish as the numerical simulation parameters. The values of $\alpha_{r}, \beta_{r}$, and $\sigma_{r}$ fluctuated significantly between 2013 and 2014, although less fluctuations occurred subsequently. In addition, they became increasingly stable after 2018 , thus being suitable to set as the numerical simulation parameters. The overall regression results for the inflation and interest rates are presented in Table 2.

According to the estimation results presented in Table 2, it may be established that $\alpha_{i}=0.00008, \alpha_{r}=0.0010$, $\beta_{i}=0.0030, \beta_{r}=0.0439, \sigma_{i}=0.0038, \sigma_{r}=0.0021$, and $\rho=0$. The estimated results indicate that the parameter of inflation rate significantly differs compared with the interest rate parameter. The difference between $\beta_{i}$ and $\beta_{r}$ shows that interest rates have stronger mean-reverting characteristics, whereas the inflation rate indicates stronger cyclical volatility. This verifies the low correlation result between inflation rate and interest rate as obtained in the previous article. Through the estimated parameters, it may be calculated that the long-term equilibrium inflation rate is $\alpha_{i} / \beta_{i}=0.0267$, while there is a long-term equilibrium interest rate $\alpha_{r} / \beta_{r}=0.0228$, with both being approximate to the descriptive statistical mean of the previous sample, thus indicating that the estimated results have greater credibility. In addition, the long-term equilibrium inflation rate is below 0.03 , suggesting that China's inflation rate has remained at a low level over a significant period of time.

Long-term interest rates are representative of market expectations regarding future economy growth, while shortterm interest rates reflect the money markets' supply and demand. Differences exist between the interest rates for bonds on different maturities. The longer the maturity of 
TABLE 1: Descriptive statistics of interest rates and inflation rates.

\begin{tabular}{lccccc}
\hline Variables & Mean & Standard deviation & Minimum value & Maximum value & Quantity \\
\hline$r$ & 0.0233 & 0.00714 & 0.0077 & 0.1220 & 3427 \\
$i$ & 0.0270 & 0.0866 & -0.1940 & 0.5590 & 9075 \\
\hline
\end{tabular}

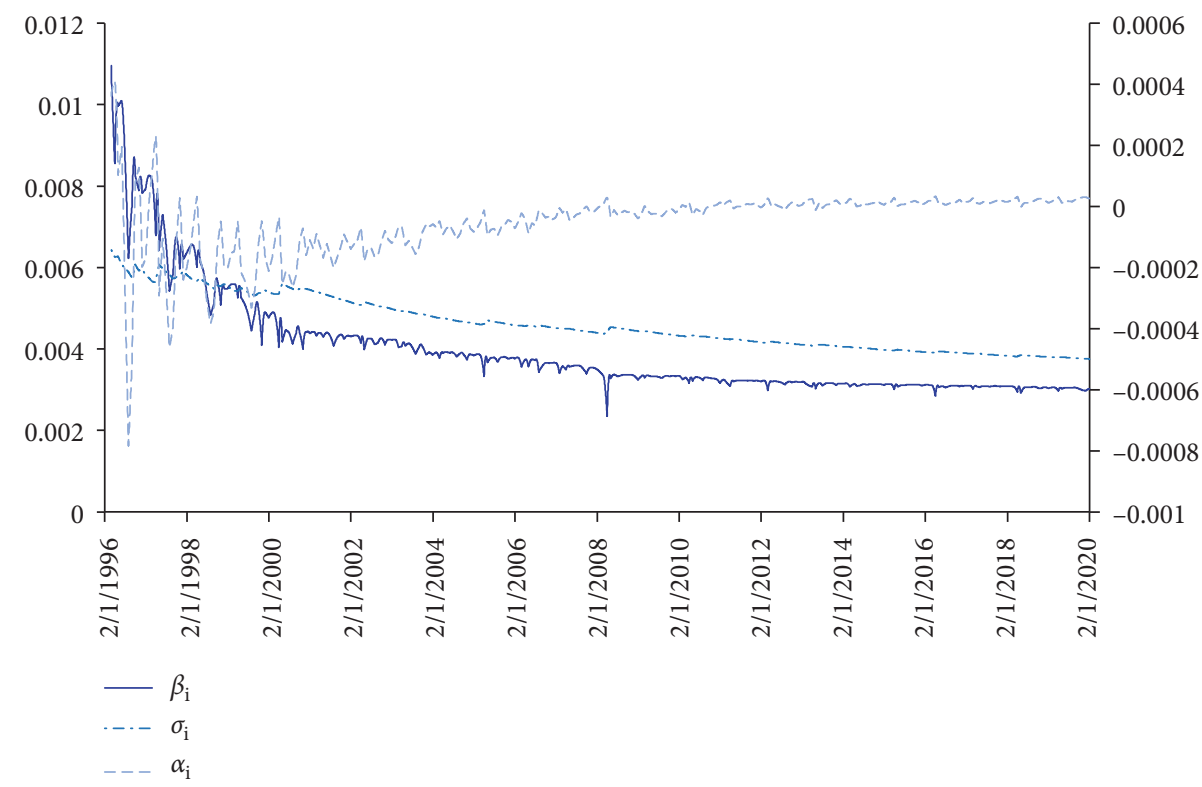

Figure 1: Changes of the parameters in the inflation rate model from 1996 to 2020 (note: the value of $\alpha_{i}$ is the right-side secondary axis, and the remaining variables are the left-side primary axis).

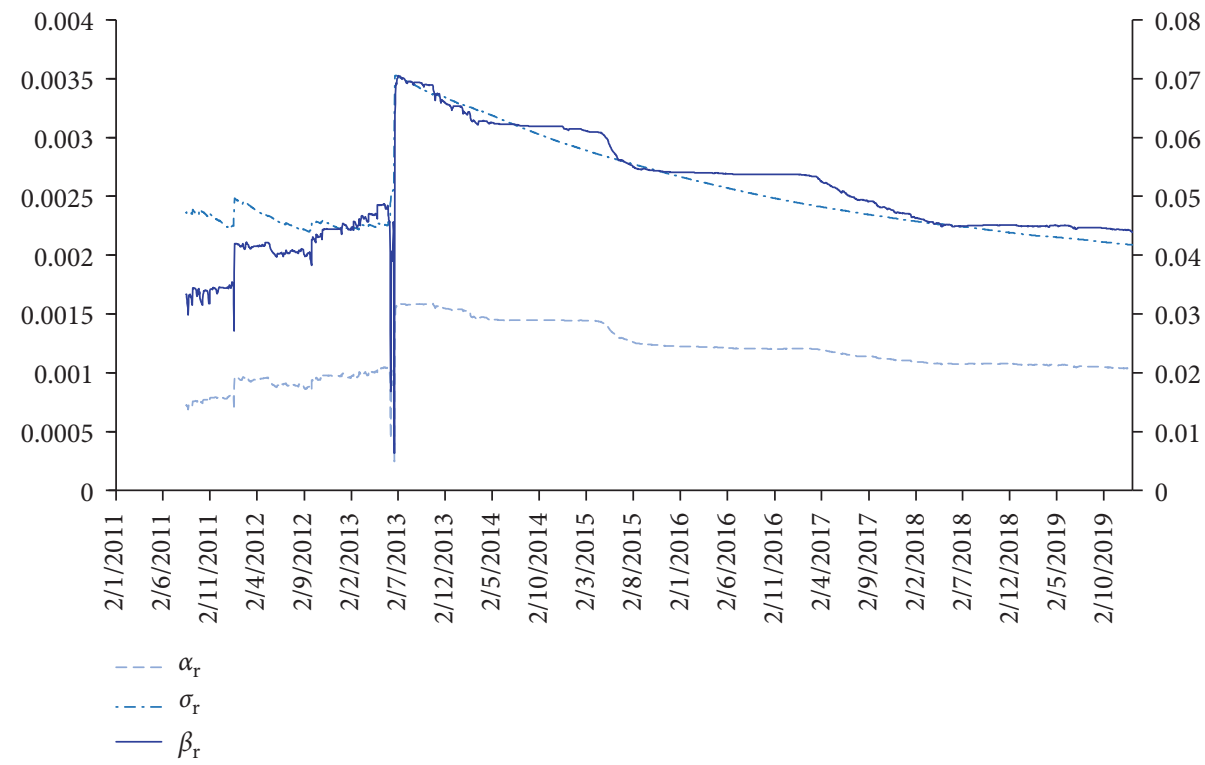

Figure 2: Changes of the parameters in the interest rate model from 2011 to 2020 (note: the value of $\beta_{r}$ is the right-side secondary axis, and the remaining variables are the left-side primary axis).

bonds, the greater the risk that investors will suffer. The difference between the long-term interest rate and the shortterm interest rate conveys the compensation of the term risk, referred to as the risk premium. This paper adopts the yield to maturity of local government bonds (1 year) minus the yield to maturity of local government bonds (0 year/overnight) to establish the interest rate risk premium. The specific time series data are presented in Figure 3. The mean value of the risk premium is 0.0086 , while the standard deviation is 0.0043 . It is apparent from Figure 3 that besides 
TABLE 2: Model parameter estimation results.

\begin{tabular}{lcccccc}
\hline $\begin{array}{l}\text { Dependent } \\
\text { variable }\end{array}$ & Constant & Slope & Standard deviation & GOF & $\begin{array}{c}F \text {-test } \\
\text { Sample size }\end{array}$ & $\begin{array}{c}\text { Estimation } \\
\text { method }\end{array}$ \\
\hline$i$ & $\alpha_{i} 0.00008^{*}(1.89)$ & $1-\beta_{i} 0.9970^{* * *}(1177.85)$ & $\sigma_{i} 0.0038$ & $R^{2} 0.9981$ & $p=0.0000$ & 9073 \\
$r$ & $\alpha_{r} 0.0010^{* * *}(2.66)$ & $1-\beta_{r} 0.9560^{* * *}(891.77)$ & $\sigma_{r} 0.0021$ & $R^{2} 0.9144$ & $p=0.0000$ & 3425 \\
\hline
\end{tabular}

Note. The value in the parentheses below the regression coefficient is the $p$ value of the coefficient; ${ }^{*},{ }^{* *}$, and ${ }^{* * *}$ indicate significance at the $10 \%, 5 \%$, and $1 \%$ significance levels, respectively.

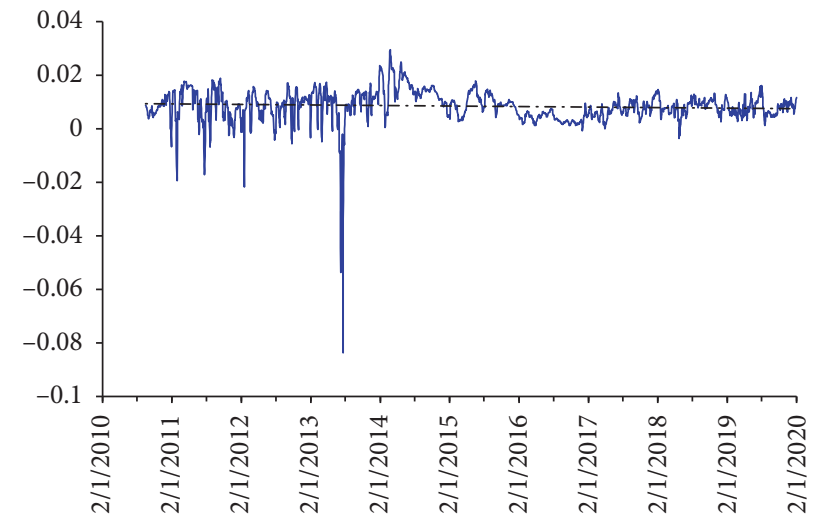

Figure 3: Interest rate risk premium from 2010 to 2020.

the period between May and June 2013, short-term interest rates rose dramatically as a consequence of insufficient liquidity in the interbank market, with the long-term interest rates being surpassed. China's interest rate risk premium remained stable for a long period of time post-2010.

Peter and Oreste [30] considered the inflation risk premium over a period of time to be equal to the anticipated inflation rate within this period of time, minus the expected inflation target. This article combines the interest rate risk premium algorithm with Peter and Oreste's perspective. With the inflation risk premium equal to the mean inflation rate within the 12 months minus the current inflation rate, formula (21) may be presented as

$$
\lambda_{i}(t)=\frac{1}{12} \sum_{j=1}^{12} i_{t-6+j}-i(t) .
$$

Figure 4 presents the results obtained via the data calculation. The mean value of the inflation risk premium is -0.0004 , while the standard deviation is 0.0724 . The inflation risk premium fluctuated markedly since the early stage, after which it gradually decreased. This potentially contributed to the noted drastic fluctuations. The mean value is rather close to 0 , while the inflation risk premium graph is essentially a long-term mean regression model around the average value. Accordingly, the trend for the inflation risk premium has remained stable over the long term.

Through the above estimation process, all the parameters required by model (18) are obtained: $\alpha_{i}=0.00008$, $\alpha_{i}=0.00008, \alpha_{r}=0.0010, \beta_{i}=0.0030, \beta_{r}=0.0439, \sigma_{i}=$ $0.0038, \sigma_{r}=0.0021, \mathrm{cov}=0, \lambda_{i}=0$, and $\lambda_{r}=0$. This study's proposed government subsidy calculation formula provides a preevaluation model for the government during an

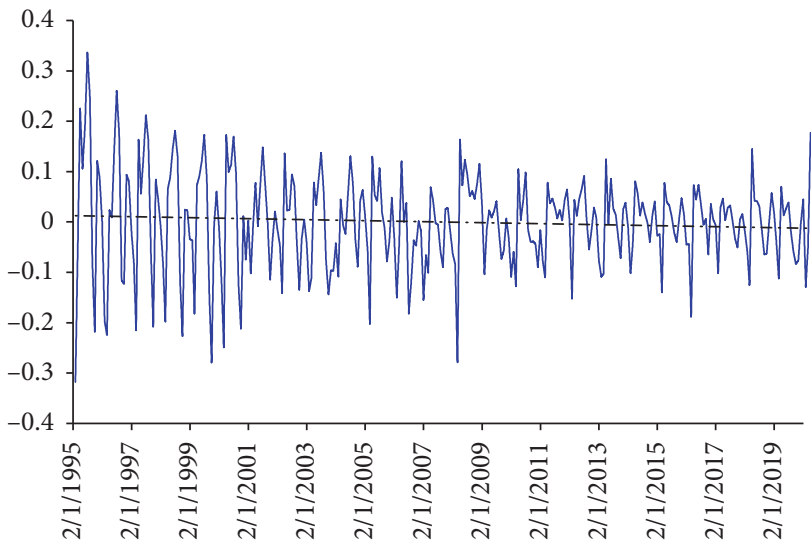

FIGURE 4: Inflation risk premium from 1995 to 2020.

infrastructure project's decision-making stage. At this present point in time, the project's analysis is undertaken based on historical data. If it is necessary to constantly evaluate the subsidies or risks confronted by the project during the subsequent franchise period, the aforementioned rolling regression method may be applied for calculating the parameters, having obtained the updated data.

\section{Numerical Simulation}

5.1. Simulation of the Government Subsidy. The basic income and cost data for $N$ City Metro Line 3 over the franchise period from 2021 to 2045 are presented in Table 3.

Adopting the previously estimated parameters and formulas (15) and (16), this research established the social capital inflation commitment parameter $q$ in $E\left[\max \left(e^{\widetilde{D}_{i}(0 . t)}-q, 1\right) e^{\widetilde{D}_{r}(0 . t)}\right]$ to 0 temporarily, with MATLAB then used to perform 1000 times $($ Repeat $=1000$ ) Monte Carlo on the interest rate and inflation operator simulation. Daily discount operator and inflation operator values between 1 January 2021 and 31 December 2045 were obtained. With the simulation time limit being 25 years, a simulation step (time step) was recorded every single day, with the total step length being 9125. The simulated discount and inflation operator data for the franchise period between 2021 and 2045 are presented in Table 4.

The simulation process of the discount operator and the inflation operator is presented in Figures 5(a) and 5(b).

The discount operator curve gradually diverges from the initiation point, progressively increasing from 1 . The final value is distributed in the interval of 1.5 to 2.8 , with the majority of curve points being located around 2. The inflation operator curve presents a gentle exponential growth, while as formula 
Table 3: The basic income and cost data of N City Metro Line 3 Project.

\begin{tabular}{|c|c|c|c|c|c|}
\hline Year & $\begin{array}{l}\text { Forecast daily passenger volume } \\
(10,000 \text { people })\end{array}$ & $\begin{array}{l}\text { Average length of } \\
\text { haul }(\mathrm{km})\end{array}$ & $\begin{array}{l}\text { Ticket income } \\
(10,000 \mathrm{RMB})\end{array}$ & $\begin{array}{l}\text { Operating costs } \\
(10,000 \mathrm{RMB})\end{array}$ & $\begin{array}{c}\text { Operation loss subsidy } \\
(10,000 \mathrm{RMB})\end{array}$ \\
\hline 2021 & 26.04 & 7.81 & $16,156.04$ & $29,093.19$ & $13,132.13$ \\
\hline 2022 & 28.97 & 7.66 & $17,611.39$ & $29,609.81$ & $12,021.59$ \\
\hline 2023 & 31.90 & 7.50 & $18,993.68$ & $32,192.91$ & $13,247.55$ \\
\hline 2024 & 34.83 & 7.34 & $20,302.89$ & $32,239.77$ & $11,793.03$ \\
\hline 2025 & 37.76 & 7.19 & $21,539.03$ & $32,286.63$ & $10,422.54$ \\
\hline 2026 & 40.69 & 7.03 & $22,702.10$ & $32,333.49$ & 9136.09 \\
\hline 2027 & 43.61 & 6.87 & $23,792.11$ & $32,380.35$ & 7933.66 \\
\hline 2028 & 46.54 & 6.71 & $24,809.04$ & $32,427.21$ & 6815.27 \\
\hline 2029 & 49.47 & 6.56 & $25,752.90$ & $32,878.31$ & 6221.52 \\
\hline 2030 & 52.40 & 6.40 & $26,623.70$ & $34,727.07$ & 7235.25 \\
\hline 2031 & 54.03 & 6.42 & $27,539.36$ & $34,770.80$ & 6229.91 \\
\hline 2032 & 55.67 & 6.44 & $28,460.21$ & $34,814.54$ & 5218.60 \\
\hline 2033 & 57.30 & 6.46 & $29,386.25$ & $34,858.28$ & 4201.33 \\
\hline 2034 & 58.93 & 6.48 & $30,317.48$ & $34,902.01$ & 3178.09 \\
\hline 2035 & 60.57 & 6.50 & $31,253.89$ & $34,945.75$ & 2148.89 \\
\hline 2036 & 62.20 & 6.52 & $32,195.49$ & $34,989.48$ & 1113.72 \\
\hline 2037 & 63.83 & 6.54 & $33,142.28$ & $35,033.22$ & 72.59 \\
\hline 2038 & 65.47 & 6.56 & $34,094.25$ & $35,076.96$ & -974.51 \\
\hline 2039 & 67.10 & 6.58 & $35,051.41$ & $35,120.69$ & -2027.57 \\
\hline 2040 & 68.73 & 6.60 & $36,013.76$ & $35,164.43$ & -3086.59 \\
\hline 2041 & 70.37 & 6.62 & $36,981.29$ & $35,208.16$ & -4151.58 \\
\hline 2042 & 72.00 & 6.64 & $37,954.01$ & $35,251.90$ & -5222.54 \\
\hline 2043 & 73.63 & 6.66 & $38,931.91$ & $35,295.64$ & -6299.46 \\
\hline 2044 & 75.27 & 6.68 & $39,915.01$ & $35,925.52$ & -6743.45 \\
\hline 2045 & 76.90 & 6.70 & $40,903.29$ & $41,044.09$ & -2300.72 \\
\hline
\end{tabular}

TABLe 4: Annual discount and inflation operator.

\begin{tabular}{lccccc}
\hline Year & IA & RA & Year & IA & RA \\
\hline 2021 & 1.03 & 1.03 & 2034 & 1.47 & 1.51 \\
2022 & 1.06 & 1.07 & 2035 & 1.55 & 1.54 \\
2023 & 1.08 & 1.10 & 2036 & 1.59 & 1.58 \\
2024 & 1.11 & 1.14 & 2037 & 1.64 & 1.68 \\
2025 & 1.15 & 1.17 & 2038 & 1.73 & 1.78 \\
2026 & 1.18 & 1.21 & 2039 & 1.72 \\
2027 & 1.21 & 1.25 & 2040 & 1.83 & 1.77 \\
2028 & 1.24 & 1.29 & 2041 & 1.89 \\
2029 & 1.28 & 1.33 & 2042 & 1.94 \\
2030 & 1.31 & 1.37 & 2043 & 1.92 \\
2031 & 1.35 & 1.41 & 2044 & 2.00 \\
2032 & 1.39 & 1.45 & 2045 & 2.03 \\
2033 & 1.43 & 1.49 & & 2.09 \\
\hline
\end{tabular}

(15) shows, the final value is located between 0 and 4 . The 1000 Monte Carlo simulation values are averaged so as to obtain the final simulation value for the interest rate and inflation operator at each point of time. The simulated IA curve presented in Figure 6 is the result of the inflation operator simulation. Evidently, the real value fluctuates around the simulated value when compared to the real inflation operator between 1995 and 2020 (1995 to 2020 IA). Comparable growth trends were apparent for these two curves, thus confirming that the simulated value may fit the real value rather well. Consequently, it is reasonable to utilise the simulated value to estimate the future in accordance with the historical information.

According to the calculated inflation operator, discount operator, operating income, and operating cost data, this research adopts formula (9) to calculate the present value of inflation-adjusted operating income, in addition to the present value of inflation-adjusted total operating costs. The results are presented in Table 5 .

According to the data in Table 5, the present value of operating income should be subtracted from the present value of inflation-adjusted operating costs per annum, with a per annum accumulation of the results as formula (17) presents. Based on an annual increase in the operating income according to annual inflation, with the social capital inflation assumption parameter $q$ being 0 (which is to say, the government assumes all inflation risks), the final calculated current value $(S)$ of the inflation-adjusted government subsidy is CNY 118.672 million. Compared with the current value of subsidies (CNY 102.941 million) calculated according to traditional calculation methods, an increase of $15.4 \%$ has 


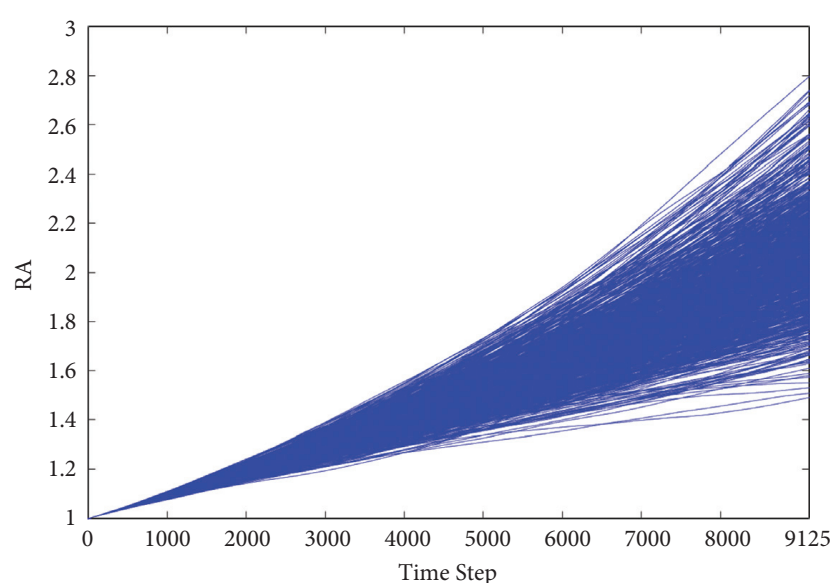

(a)

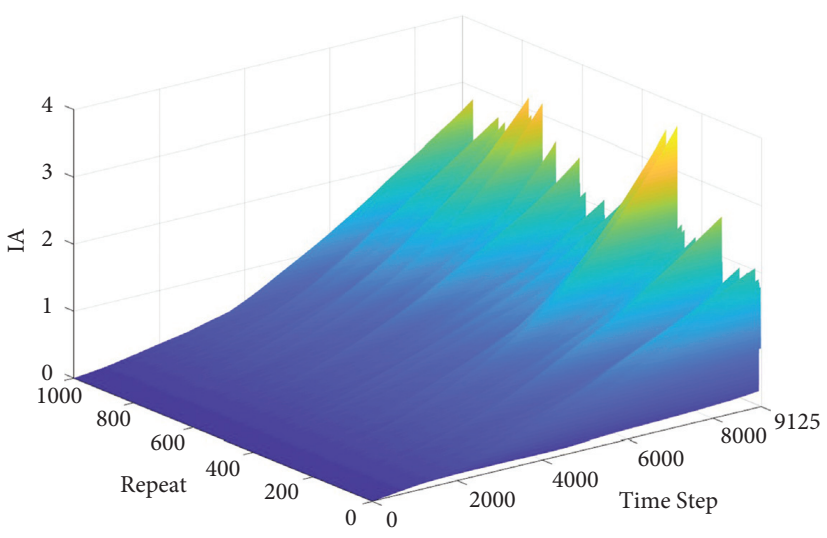

(b)

FIgURE 5: (a) The simulation results of the discount operator (RA) and (b) inflation operator (IA) simulation result graph.

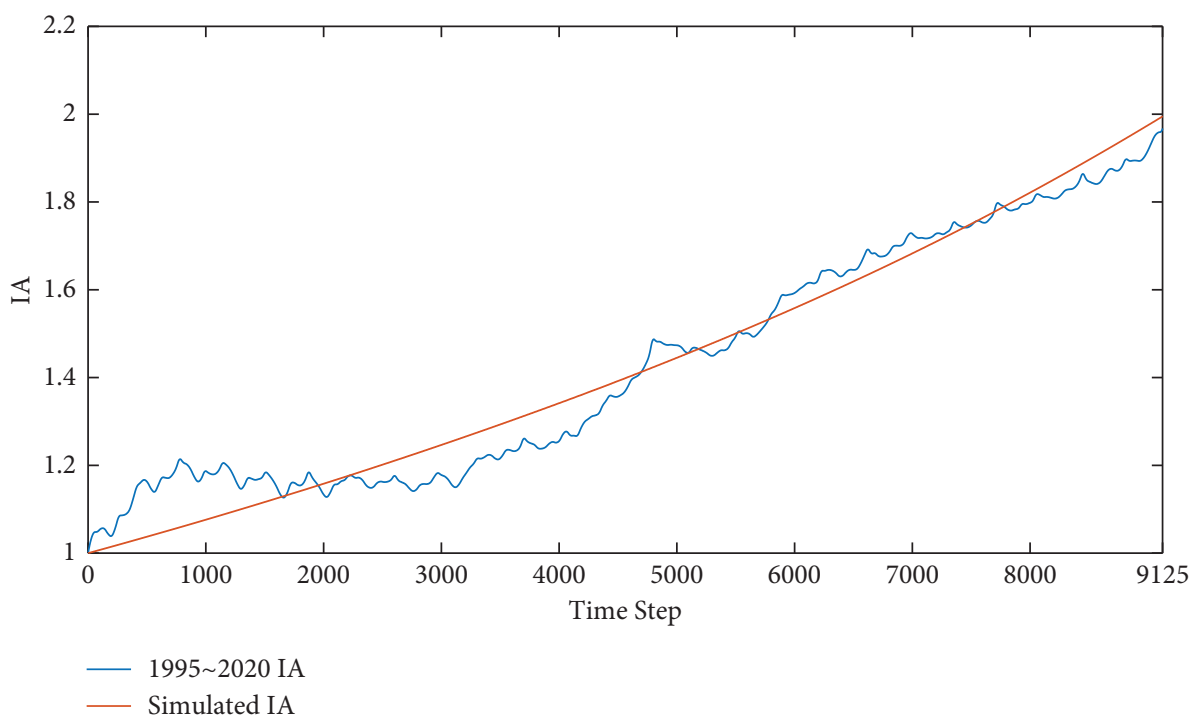

FiguRE 6: Comparison of real inflation operator and simulated inflation operator from 1995 to 2020.

occurred. Therefore, it is apparent that inflation has considerably affected the operating loss subsidies.

5.2. Changes in Inflation Risk-Sharing. In formula (18), parameter $q$ in the discount rate $E\left[\max \left(e^{\widetilde{D}_{i}(0 . t)}-q, 1\right)\right.$ $\left.e^{\widetilde{D}_{r}(0 . t)}\right]$ represents the social capital's commitment to inflation. Given the risk-sharing between the government and social capital, parameter $q$ varies between 0 and 0.2 ; thus, the cumulative inflation that the social capital will bear is $0 \%$ to $20 \%$, while the government will bear the outstanding inflation risk. In the context of the operating subsidy income being adjusted according to annual inflation, the result of the change in the present value of the simulated subsidy is presented in Figure 7. The subsidies' present value declines in relation to the increase in social capital's inflation burden, presenting an inverse proportional function relationship. Based on the observation presented in Figure 7, it is apparent that the zero point of the second derivative lies approximately between 0.2 and 0.3 . In this case, the social capital inflation risk taken on by the government and social capital will be situated in the range of approximately $20 \%$ to $30 \%$. This may significantly diminish the government's risk exposure $s$ without making social capital unacceptable.

5.3. Toll Adjustment Frequency. In 2019, large-scale riots broke out in Santiago, the capital of Chile, as a consequence of a limited increase in subway fares. Despite the riots caused by the fare rise being an extreme event with only a limited probability of occurring, it may also reflect how resistance and the social impact of quasi-public products' price increases are relevant to a certain extent. Government and social capital are supposed to take into account the mechanism and frequency of the increase in quasi-public product prices influenced by inflation. Otherwise, they can have a significant effect on the project's government subsidies or social capital profits. Figure 8 
TABLE 5: Present value of inflation-adjusted operating income and present value of inflation-adjusted operating cost (unit: 10,000 RMB).

\begin{tabular}{cccccc}
\hline Year & $\begin{array}{c}\text { Inflation-adjusted operating } \\
\text { income }\end{array}$ & $\begin{array}{c}\text { Inflation-adjusted total } \\
\text { operating costs }\end{array}$ & Year & $\begin{array}{c}\text { Inflation-adjusted operating } \\
\text { income }\end{array}$ & $\begin{array}{c}\text { Inflation-adjusted total } \\
\text { operating costs }\end{array}$ \\
\hline 2021 & $16,061.37$ & $28,922.70$ & 2034 & $28,897.22$ & $33,266.99$ \\
2022 & $17,413.94$ & $29,277.83$ & 2035 & $29,758.60$ & $33,273.82$ \\
2023 & $18,687.31$ & $31,673.65$ & 2036 & $30,633.69$ & $33,292.15$ \\
2024 & $19,885.47$ & $31,576.93$ & 2037 & $31,525.15$ & $33,323.83$ \\
2025 & $21,007.83$ & $31,490.37$ & 2038 & $32,429.66$ & $33,364.38$ \\
2026 & $22,058.39$ & $31,416.69$ & 2039 & $33,345.00$ & $33,410.90$ \\
2027 & $23,037.30$ & $31,353.08$ & 2040 & $34,277.75$ & $33,536.23$ \\
2028 & $23,945.18$ & $31,298.09$ & 2041 & $35,225.15$ & $33,620.58$ \\
2029 & $24,786.09$ & $31,643.99$ & 2042 & $36,197.64$ & $33,716.20$ \\
2030 & $25,559.07$ & $33,338.40$ & 2043 & $37,189.76$ & $34,375.25$ \\
2031 & $26,377.91$ & $33,304.37$ & 2044 & $39,192.59$ & $39,345.66$ \\
2032 & $27,207.24$ & $33,281.81$ & 2045 & $39,210.68$ & \\
2033 & $28,049.50$ & $33,272.60$ & & & \\
\hline
\end{tabular}

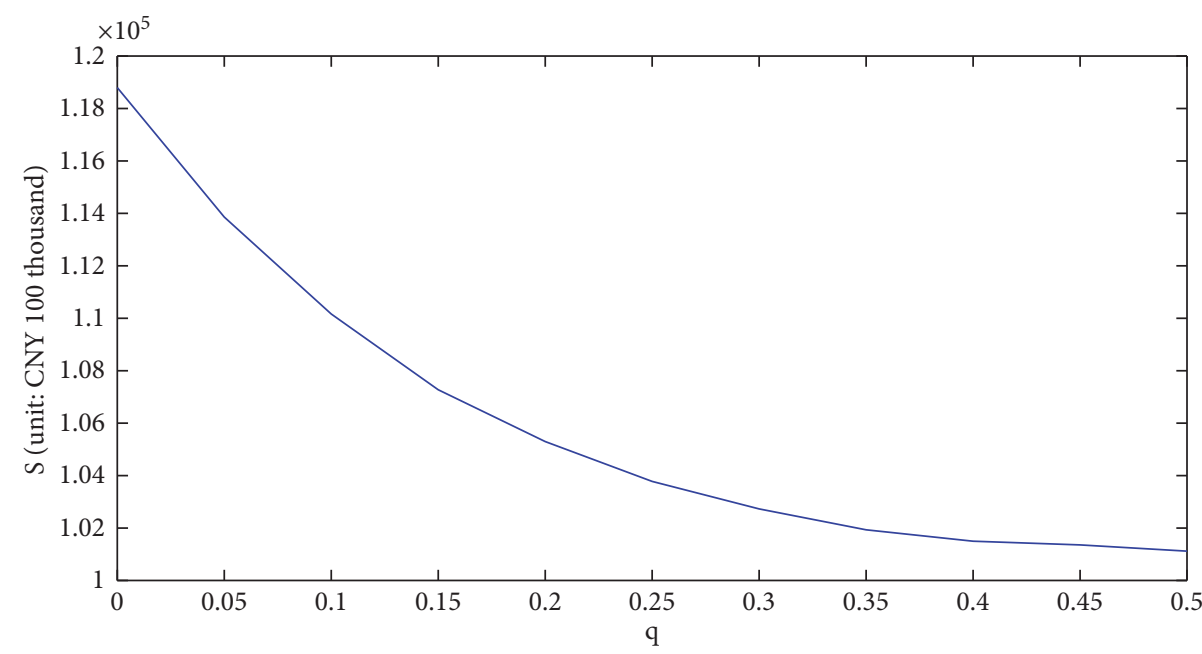

FIgURE 7: Simulation of the present value of subsidies based on social capital inflation $(q)$.

illustrates how the government's operating loss subsidies effect tolls when the government comprehensively takes on the inflation risk $(q=0)$. As Figure 8 presents, tolls are adjusted in accordance with inflation every $10,5,3$, and 1 year, thereby markedly increasing project operating income and thereby reducing government operating loss subsidies. However, government operating loss subsidies decline alongside the frequency of toll adjustments increases. The sum of the present value of government operating loss subsidies declined by $60 \%$ between once a year and once a decade. This indicates that the frequency of adjusting tolls according to inflation significantly affects government operating loss subsidies.

5.4. Changes in the Present Value of Subsidies in a Multidimensional Situation. In the multidimensional case, numerous variables potentially affect the present value of subsidies. Figure 9(a) simulates how the subsidy's present value will alter according to differing rates of interest and inflation. The allowance of operating losses increases as inflation rises, while the allowance of operating losses declines as interest rates rise. In addition, inflation rate has a larger slope in relation to operating loss subsidy, thus suggesting that the inflation rate affects the operating subsidy to a greater extent than the interest rate. Figure 9(b) simulates the effect of inflation volatility and inflation rates on the operating subsidies' present value. Figure 9 clearly shows that the inflation rate is positively correlated with the present value of operating subsidies. Meanwhile, volatility is positively correlated with the present value of operating allowances. The effect of inflation volatility on the present value of subsidies is characterised by a large slope, thus suggesting that operating subsidies' present value is characterised by greater sensitive to volatility. The greater the volatility, the more likely that inflation will occur in future. Ultimately, expectations concerning future inflation have resulted in higher operating expenditure.

Figure 10(a) simulates the effect of interest rate volatility and interest rates on the subsidies' present value. The figure conveys that interest rate volatility is positively correlated with the subsidy's present value, while the slope of the interest rate volatility is greater. Therefore, the present value of subsidies appears to be more sensitive to interest rate volatility compared to interest rates. 


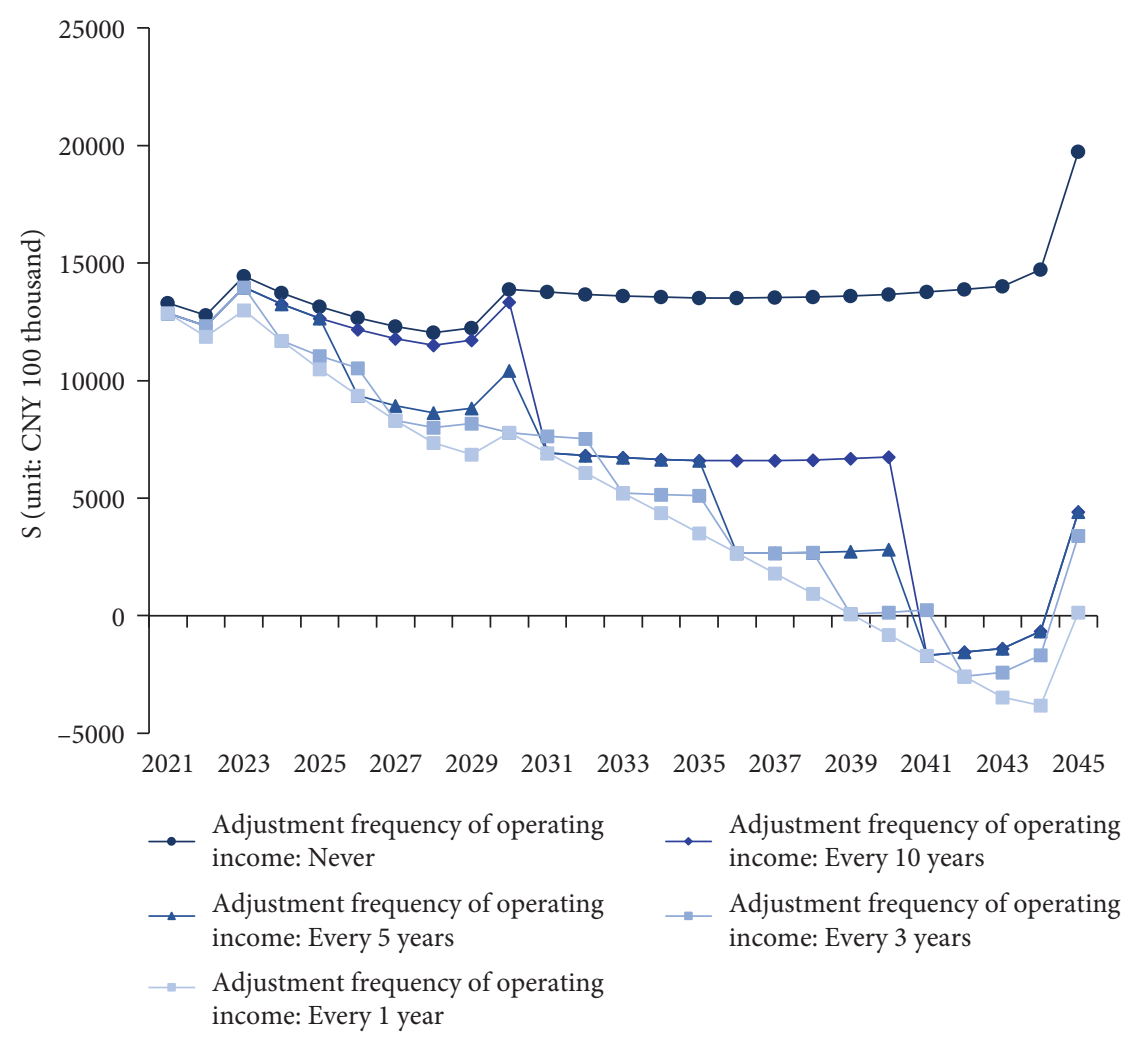

FIGURE 8: The impact of inflation-adjusted operating income.

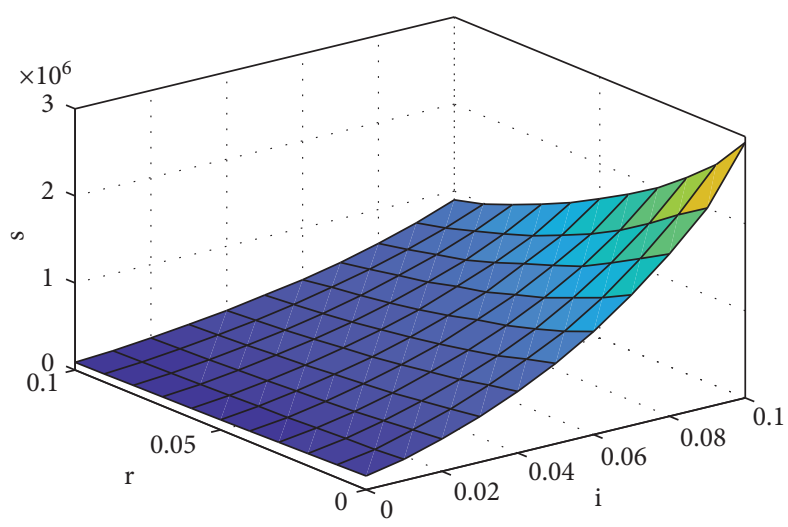

(a)

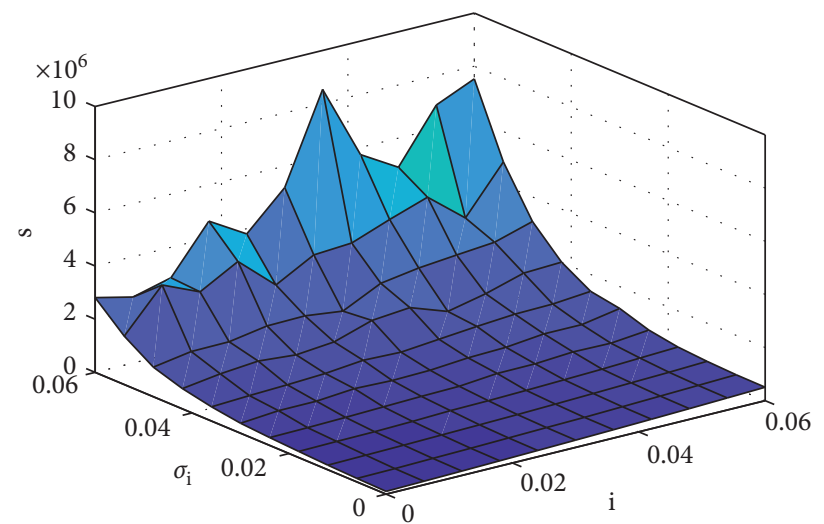

(b)

Figure 9: Present value of subsidies S (unit: CNY 100,000) based on (a) $r$ and $i$ and (b) $\sigma_{i}$ and $i$.

Figure 10(b) simulates the effect of interest rate volatility and inflation volatility on the subsidies' present value. It is observable that the slope for inflation volatility effect on the present value of subsidies exceeds that of interest rate volatility. Therefore, the present value of subsidies is characterised by greater sensitivity to inflation volatility.
Following a rigorous comparison, it may be concluded that among the four variables of inflation rate, interest rate, inflation volatility, and interest rate volatility, it is inflation volatility that has the profoundest effect on the present value of subsidies, followed by interest rate volatility, inflation rate, and then interest rate. 


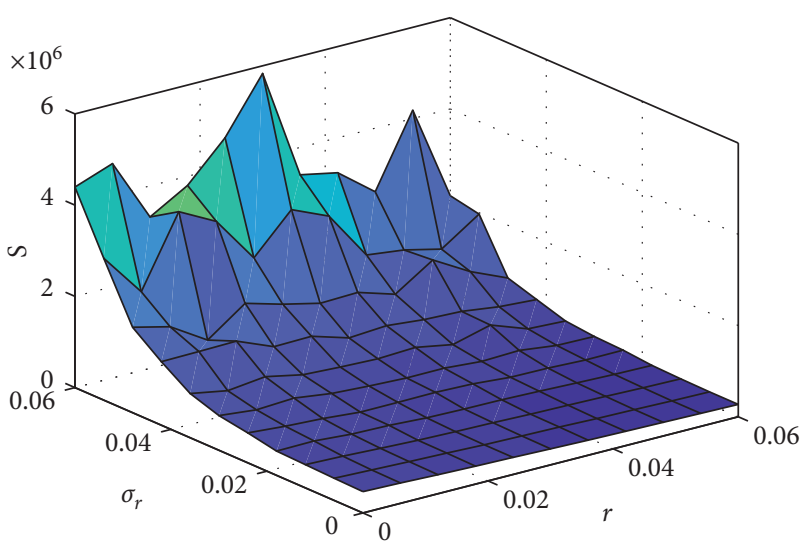

(a)

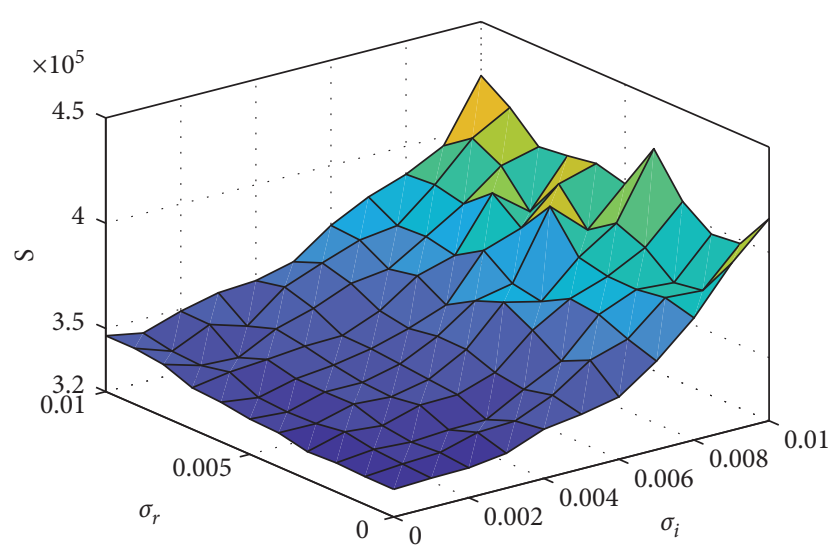

(b)

FIgURe 10: Present value of subsidies S (unit: CNY 100,000) based on (a) $\sigma_{r}$ and $r$ and (b) $\sigma_{r}$ and $\sigma_{i}$.

\section{Conclusion}

This study applied a stochastic differential equation model as well as the Monte Carlo simulation method to conduct research into government subsidies for operating loss, under the conditions of uncertain inflation rate and interest rate. Ultimately, a reasonable tool was developed through which the government can evaluate the project's operating costs and the benefits of infrastructure projects, thus enhancing the effectiveness of infrastructure projects' operations, while further promoting steady growth in China's economy.

The research was undertaken on the basis of the operating loss subsidy model of the two-factor continuous time model, including the interest rate and inflation rate. Moreover, the pertinent parameters for the operating loss subsidy model were estimated on the basis of a rolling regression and a seemingly uncorrelated regression model. Analysis of the dynamic conditions of the relevant parameters was undertaken, with the obtained parameters being established as stable and appropriate for numerical simulation. Furthermore, estimates were used to obtain the parameters. Monte Carlo simulation was adopted for the operating loss subsidy model via MATLAB, to realise the simulation calculation for the government operating loss subsidy's present value. This value is simulated in the context of inflation risk-sharing. Changes in subsidies' present value under the influence of interest rates, inflation rates, inflation rate volatility, and interest rate volatility have been determined. Furthermore, the sensitivity of operating subsidies' present value to interest rates, inflation rates, inflation volatility, and interest rate volatility has been explored.

Certain significant conclusions may be emphasised. Firstly, the dynamic random discount rate according to inflation rate and interest rate successfully simulated the effect of inflation rate and interest rate changes on the project's operating loss. In addition, accurate calculation was possible for the present value of the adjusted operating loss subsidy, alongside the present value of the risk-sharing subsidy. This may prove beneficial for the government during the project decision-making process. Secondly, the government subsidies' present value diminishes as the social capital inflation risk-sharing increases; that is, they are inversely proportional function relations. Inflation and the frequency of toll adjustments significantly affect government operating loss subsidies. During infrastructure projects' evaluation, the government should account for their adjustment mechanisms into account, while also sharing risks with social capital. Thirdly, the inflation rate, inflation volatility, and interest rate volatility are positively correlated with operating loss subsidies' present value, whereas interest rates are negatively correlated with inflation-adjusted operating loss subsidies' present value. Overall, inflation volatility has the greatest effect on subsidies' present value, followed by interest rate volatility and inflation, then interest rates. These conclusions indicate that local governments should ideally pay greater attention to inflation risks' sharing and management between the government and social capital, during the process of evaluating financial affordability and value. Moreover, it is significant to continue focusing on a more reasonable selection of discount rates. In this manner, infrastructure projects may be perceived as sound value for money, while more stable and superior economic development could be attained and effectively promoted.

\section{Data Availability}

The data used to support the findings of this study are available at the National Bureau of Statistics database via https://data.stats.gov.cn/english/easyquery.htm?cn=A01.

\section{Conflicts of Interest}

The authors declare no conflicts of interest.

\section{Acknowledgments}

The support by the National Social Science Foundation research project "the Realization PATH of Supporting the Comprehensive Construction of a Modern Country with Strong Transportation Network" (grant no. 21AZD019) is gratefully acknowledged. 


\section{References}

[1] Operation Guide for Government-Private Capital Cooperation Model (Trial), Ministry of Finance of the People's Republic of China, 2014, http://jrs.mof.gov.cn/zhengcefabu/ 201412/t20141204_1162965.htm.

[2] K. C. Lam and W. S. Chow, "The significance of financial risks in BOT procurement," Building Research \& Information, vol. 27, no. 2, pp. 84-95, 1999.

[3] J. Schaufelberger and I. Wipadapisut, "Alternate financing strategies for build-operate-transfer projects," Journal of Construction Engineering and Management, vol. 129, no. 2, 2003.

[4] L. Y. Shen, A. Platten, and X. P. Deng, "Role of public private partnerships to manage risks in public sector projects in Hong Kong," International Journal of Project Management, vol. 24, no. 7, pp. 587-594, 2006.

[5] A. Ng and M. Loosemore, "Risk allocation in the private provision of public infrastructure," International Journal of Project Management, vol. 25, no. 1, pp. 66-76, 2007.

[6] M. P. Abednego and S. O. Ogunlana, "Good project governance for proper risk allocation in public-private partnerships in Indonesia," International Journal of Project Management, vol. 24, no. 7, pp. 622-634, 2006.

[7] M. A. Safayet, M. H. Islam, and S. Ahmed, "A case study on risk management in existing construction project in Bangladesh," Journal of Logistics, Informatics and Service Science, vol. 5, no. 1, pp. 1-16, 2018.

[8] K. Ashoka and S. Shanmugathas, "Factors influencing the mark-up decisions of infrastructure projects in developing countries: the case of Sri Lanka, journal of system and management sciences," Journal of System and Management Sciences, vol. 8, no. 2, pp. 1-25, 2018.

[9] P. Lam, "A sectoral review of risks associated with major infrastructure projects," International Journal of Project Management, vol. 17, no. 2, pp. 77-87, 1999.

[10] K. T. Yeo and L. K. Robert, "Positive management of differences for risk reduction in BOT projects," International Journal of Project Management, vol. 18, no. 4, pp. 257-265, 2000.

[11] N. S. Prianka and R. Malik, "Transportation infrastructure financing: evaluation of alternatives," Journal of Infrastructure Systems, vol. 3, no. 3, pp. 111-118, 1997.

[12] L. Y. Shen, H. Li, and Q. M. Li, "Alternative concession model for build operate transfer contract projects," Journal of Construction Engineering and Management, vol. 128, no. 4, pp. 326-330, 2002.

[13] L. Y. Shen and Y. Z. Wu, "Risk concession model for build operate transfer contract projects," Journal of Construction Engineering and Management, vol. 131, no. 2, pp. 211-220, 2005.

[14] M. Wu, K. W. Chau, and Q. P. Shen, "Net asset value-based concession duration model for BOT contracts," Journal of Construction Engineering and Management, vol. 138, no. 2, pp. 304-308, 2012.

[15] S. Hanaoka and H. P. Palapus, "Reasonable concession period for build-operate-transfer road projects in the Philippines," International Journal of Project Management, vol. 30, no. 8, pp. 938-949, 2012.

[16] M. M. Alam and F. Faisal, "Public-private partnership (PPP) projection Bangladesh: current status and challenges," Journal of System and Management Sciences, vol. 8, no. 4, pp. 38-56, 2018.
[17] A. Burinskas and A. Burinskiene, "Application of gordon's growth model for the transport sector of Lithuania," Journal of Logistics, Informatics and Service Science, vol. 7, no. 1, pp. 31-41, 2020.

[18] M. S. Scholes and F. S. Black, "The pricing of options and corporate liabilities," Journal of Political Economy, vol. 81, no. 3, pp. 637-654, 1973.

[19] R. C. Merton, "Theory of rational option pricing," Bell Journal of Economics \& Management Science, vol. 4, no. 1, pp. 141-183, 1973.

[20] O. Vasicek, "An equilibrium characterization of the term structure," Journal of Financial Economics, vol. 5, no. 4, pp. $177-188,1977$.

[21] J. C. Cox, J. E. Ingersoll Jr., and S. A. Ross, "A theory of the term structure of interest rates," Econometrica, vol. 53, no. 2, pp. 385-407, 1985.

[22] D. Heath, R. Jarrow, and A. Morton, "Bond pricing and the term structure of interest rates: a new methodology for contingent claims valuation," Econometrica, vol. 60, no. 1, pp. 77-105, 1992.

[23] R. Jarrow and Y. Yildirim, "Pricing treasury inflation protected securities and related derivatives using an HJM model," Journal of Financial \& Quantitative Analysis, vol. 38, no. 2, pp. 337-358, 2003.

[24] C. Pelizzari and F. Paolo, "Pricing inflation linked bonds," Quantitative Finance, vol. 10, no. 3, pp. 279-293, 2010.

[25] M. Abrahams, T. Adrian, R. K. Crump, and E. Moench, "Pricing tips and treasuries with linear regressions," Social Science Electronic Journal, vol. 84, no. 2, pp. 182-200, 2012.

[26] S. Dajčman, "Nonlinear effects of monetary policy on the consumer loans market," Economic Computation \& Economic Cybernetics Studies \& Research, vol. 54, no. 2, pp. 229-241, 2020.

[27] R. S. Gurkaynak, B. P. Sack, and J. H. Wright, "The TIPS yield curve and inflation compensation," in Proceedings of the Working Papers-U.S. Federal Reserve Board's Finance \& Economic Discussion Series, Washington, D.C., USA, November 2007.

[28] E.-D. Comanita, M. Gavrilescu, C. Ghinea et al., "Challenges and oportunities in green plastics: an assessment using the ELECTRE decision-aid method," Environmental Engineering and Management Journal, vol. 14, no. 3, pp. 689-702, 2015.

[29] E. Comăniţă, P. Cozma, I. Simion, M. Roşca, and M. Gavrilescu, "Evaluation of eco-efficiency by multicriteria decision analysis. case study of eco-innovated and ecodesigned products from recyclable waste," Environmental Engineering and Management Journal, vol. 17, pp. 1791-1804, 2018.

[30] H. Peter and T. Oreste, "Inflation risk premia in the term structure of interest rates," Journal of the European Economic Association, vol. 10, no. 3, pp. 634-657, 2012. 